\title{
Profile of Knee's Bone and Joint Tuberculosis in Adults: About 33 Cases
}

\author{
Touré Stanislas', Bana Abdoulaye ${ }^{1}$, Koné Samba ${ }^{1}$, Soumaro Kanaté1, \\ Gbané Mariam², Sévédé Daouda ${ }^{3}$, Ouali Boubacar², Megne Estelle², \\ Traoré Moriba², Ngandeu Nawé Astrid ${ }^{2}$ \\ ${ }^{1}$ Service de Chirurgie Orthopédique et Traumatologique du C.H.U. de Cocody, Abidjan, Ivory Coast \\ ${ }^{2}$ Service de Rhumatologie du C.H.U. de Cocody, Abidjan, Ivory Coast \\ ${ }^{3}$ Service de Bactériologie Institut Pasteur C.H.U. de Cocody, Abidjan, Ivory Coast \\ Email: ${ }^{*}$ k.samba06@gmail.com
}

Received 21 June 2015; accepted 21 July 2015; published 24 July 2015

Copyright (C) 2015 by authors and Scientific Research Publishing Inc.

This work is licensed under the Creative Commons Attribution International License (CC BY). http://creativecommons.org/licenses/by/4.0/

(c) $\underset{\mathrm{EY}}{\mathrm{B}}$ Open Access

\section{Abstract}

The authors report toward a monocentric retrospective and descriptive study on a 08 year period, 33 cases of knee osteoarticular tuberculosis (OAT) of adult, certified by bacteriologic and/or histolological evidence proof of the sample (synovial biopsy) after a knee arthrotomy. There were 07 cases of arthritis and 26 cases of osteoarthritis. The treatment of knee OAT was medical (anti-tubercular poly-chemotherapy) on one year duration. The surgery was useful in front of some clinical presentations. After a minimum of 18 months, a functional evaluation was done following the Lequesne algo-functionnal index. None had signs of local recurrence testifying the adequacy of medical treatment, even if it is long and binding. The main of our case series is to establish an epidemiological, clinical and biological profile of the knee tuberculosis of adult and to research elements of prognosis through an analysis of results.

\section{Keywords}

Knee, Bone and Joint Tuberculosis, Adult, Prognosis Factors

\section{Introduction}

Tuberculosis is an infectious disease, which constitutes a veritable problem of public health inside countries on developing process, where it rages on endemic mode.

Surely it predilection siege stays lungs but it can also affect other extra-pulmonary signs like joins.

\footnotetext{
${ }^{*}$ Corresponding author.
}

How to cite this paper: Stanislas, T., Abdoulaye, B., Samba, K., Kanaté, S., Mariam, G., Daouda, S., Boubacar, O., Estelle, M., Moriba, T. and Astrid, N.N. (2015) Profile of Knee's Bone and Joint Tuberculosis in Adults: About 33 Cases. Open Journal of Orthopedics, 5, 189-197. http://dx.doi.org/10.4236/ojo.2015.57026 
The knee tuberculosis or white knee tumor is defined by the set of clinical and paraclinical manifestations linked to the presence and pullulating of Tubercle Bacillus (TB) [1] inside the knee join.

The osteoarticular tuberculosis (OAT) represents $11 \%$ to $15 \%$ of extra pulmonary tuberculosis [2], and the knee damage is actually the second localization after the spine one [2] [3].

From high prevalence in developing countries since a decade, we are assisting at an increase of tuberculosis in developed countries, mainly on immigrants and old peoples [2] [3].

Tuberculous arthritis is rare [4] [5]. Following promoting factors (terrain, environment), the articular damage can be secondary to an inoculation, invasion via a focal point nearing point of tuberculous osteomyelitis or can result in a hematogenous dissemination.

At the beginning, lesions are essentially synovial (arthritis) and it is secondary that cartilage and under chondral bone are touched (osteoarthritis).

The TB will induce clinical disorders, biological and radiological, which conducts to the diagnostic. The certitude diagnostic is sometimes late due to an insidious installation; it is based input on evidence of the germ by bacteriological and/or histological proof on samples.

The treatment is mainly medical. Surgery has no interest and is most of the time associated to a medical treatment in some indications (abscess drainage, synovectomy, articular debridement, sequestrectomy etc.).

This pathology can affect all ages. Within the extra vertebral OAT, studies only on knee damages are not many.

We report by this monocentric retrospective and descriptive study, 33 cases of knee OAT on adults put on evidence by bacteriological and/or anatomopathological proofs after a knee arthrotomy.

The aim was to establish an epidemiological, clinical and biological profile of the knee tuberculosis in adult, and to research elements for prognostic through results analysis.

\section{Patients and Method}

This is a retrospective and descriptive study based on the analysis of patients files treated in the traumatology/ orthopedic unit of hospital and university center of Cocody during the period from 2004 to 2012.

Thirty-three cases of knee tuberculosis were collected during this period. Some patients $(n=13)$ were sent by the Rheumatology department of the same center for a biopsy diagnostic purpose in front of a strong clinical suspicion and lack of certitude diagnosis.

An articular draining was realized in the pre-operative period $(n=8)$ or during the surgery $(n=25)$.

A knee arthrotomy was performed on 28 patients by a first surgical anterior-medial or anterior-lateral. During the arthrotomy, multiple biopsy specimens (capsule, receivers) were made as well as other surgical gestures (drainage of collections, sequestectomy, articular washes).

In post-operative period, immobilization equipment was implemented on the knee during maximum 15 to 21 days, associated with a functional rehabilitation.

The certitude diagnosis is based on the bacteriology (liquid puncture, surgical specimens) and the histology (samples anatomo-pathology).

For all of these patients, when the diagnosis was confirmed, a TB multidrug therapy (rifampicin, isoniazid, Pyrazinamide and Ethambutol) was established according to the following regimen.

Patients were reviewed at 1 month, 3 months, 6 months and 12 months. The following data were considered: clinical examination, epidemiology, familial survey, biological investigations (Full Blood count/FBC; Erythrocytes sedimentation rate/ESR; C-reactive protein/CRP), imagery investigations (standard X ray, and Computerized Tomography/CT-scan or magnetic resonance imaging/MRI), tuberculin intradermal test (Ti-T) et and spit exam (it was asked in front of strong presumptive arguments) and evolution.

After of minimum 18 months, a functional evaluation was done following the algo-functionnal Lequesne in$\operatorname{dex}[6]$.

\section{Results}

\subsection{Epidemiological Aspects}

The hospital incidence was $04.87 \%$. The average age was 34 years, with extremes of 19 and 62 years. Twenty-six patients were from disadvantaged socio-professional environments. 


\subsection{Diagnosis Orientation}

\subsubsection{Clinical}

Clinical manifestations are listed on (Table 1). The main clinical reasons were: the pain of the knee ( $\mathrm{n}=33$ cases), functional disturbance $(\mathrm{n}=31)$ and swelling $(\mathrm{n}=29)$ (Figure 1$)$. The average progression duration was 12 weeks with extremes of 05 weeks and 18 months. In this series, night fever, night sweat and weight loss were the most frequent (Table 1$)$. The right knee was mostly attacked $(n=24)$. There was no bilateral damage.

The past medical history study revealed a notion of tuberculous contact in 17 patients; pulmonary tuberculosis on 04 patients; HIV infections on 05 patients; diabetes mellitus on 03 patients and hemoglobinopathy on 03 patients.

\subsubsection{Biological}

The biology results are reported in Table 2. Blood count was permanently disrupted and varying importance.

We noticed a microcytic hypochromic (20 cases) anaemia (31 cases), associated to a thrombocytopenia (8 cases). This thrombocytopenia was always registered in a pancytopenia context (5 cases).

All of them had an accelerated ESR. The mean of ESR was higher than $40 \mathrm{~mm}$ at the first hour (H1) and varied from 60 up to $100 \mathrm{~mm}$ at the second hour (H2). The mean of CRP level was $37.2 \mathrm{mg} / \mathrm{l}$.

The tuberculin intradermal test (Ti-T) performed on 29 patients was phlyctenular in 16 patients, negative on 13 cases and the result reading was questionable on 04 cases.

Table 1. Main clinical manifestations of knee tuberculosis on the 33 patients.

\begin{tabular}{|c|c|c|c|}
\hline \multicolumn{2}{|c|}{ Clinical exam } & \multirow{2}{*}{$\begin{array}{c}\text { Effective (n) } \\
31\end{array}$} & \multirow{2}{*}{$\begin{array}{c}\text { Percentage (\%) } \\
93.9\end{array}$} \\
\hline \multirow{6}{*}{ Impregnation signs } & Night fever & & \\
\hline & Night perspiration & 33 & 100 \\
\hline & Anorexia & 19 & $\mathbf{5 7 . 5}$ \\
\hline & Weight loss & 29 & 87.8 \\
\hline & Asthenia & 20 & 60.6 \\
\hline & Non gravid amenorrhea & 10 & 30.3 \\
\hline \multirow{5}{*}{ Past medical history } & Pulmonary tuberculosis & 4 & 12.1 \\
\hline & HIV infection & 5 & 15.1 \\
\hline & Hemoglobinopathy & 03 & 09 \\
\hline & Tuberculous contact & 17 & 51.5 \\
\hline & Diabetes & 03 & 09 \\
\hline \multirow{4}{*}{ Functional signs } & Pain & 33 & 100 \\
\hline & Lamness & 26 & 78.7 \\
\hline & swelling & 29 & 87.8 \\
\hline & Functional disturbance & 31 & 93.9 \\
\hline \multirow{7}{*}{ Physical signs } & Vicious attitude & 29 & 87.8 \\
\hline & Movements limitation & 13 & 39.3 \\
\hline & Amyotrophy & 29 & 87.8 \\
\hline & Local inflammatory signs & 19 & 57,5 \\
\hline & Fistulization & 2 & 06.9 \\
\hline & Inguinal lymph nodes & 4 & 12.1 \\
\hline & Intra articular effusion & 30 & 90.9 \\
\hline
\end{tabular}




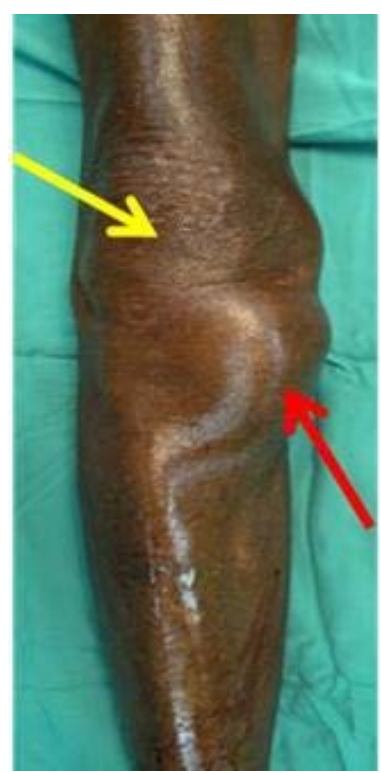

Figure 1. Local appearance of right knee, a side view: large swelling (arrow in red), patella (arrow in yellow).

Table 2. Representation of patient's biological results.

\begin{tabular}{|c|c|c|c|c|c|c|}
\hline FBC & thrombocytopenia & \multicolumn{2}{|c|}{ Hyperleucocytosis } & lymphocytosis & leucopenia & Anemia \\
\hline Effective & 8 & \multicolumn{2}{|c|}{11} & 15 & 18 & 31 \\
\hline ESR & \multicolumn{2}{|c|}{ Inferior to 20} & 20 - 39 & $40-59$ & $60-80$ & Superior to 80 \\
\hline Effective & \multicolumn{2}{|l|}{ lour } & 1 & 26 & 5 & 0 \\
\hline Effective a & \multicolumn{2}{|l|}{1 hour } & 5 & 9 & 9 & 10 \\
\hline CRP (m & \multicolumn{2}{|c|}{ Inferior to 5} & $16-30$ & \multicolumn{2}{|r|}{$31-60$} & Superior to 80 \\
\hline Effecti & \multicolumn{2}{|l|}{2} & 7 & \multicolumn{2}{|r|}{17} & 5 \\
\hline
\end{tabular}

\subsubsection{Radiological}

On the x-ray plan, the lesion only sat on the tibial plate in 25 cases and in 8 cases, it affected both the condyle and plate. There were 07 cases of arthritis and 26 cases of osteoarthritis.

The osteoarthritis found were classed by David-Chausse J. [7] and represented on Table 3 The advanced stages of osteoarthritis (III and IV) were overriding (26 cases) (Figure 2).

Knee CT-scan realized on 22 patients, showed osteoarthritis signs (Figure 3), with especially the prevalence of a fluid collection and capsular-synovial thickening. Images of sequestered bones were showed on 11 patients while 05 others had Brodie abscess (Figure 4).

\subsection{Certitude Diagnosis}

The diagnosis was sometimes directed by cytology. Cytological examination of 25 samples of articular liquid showed lymphocytic predominance with an average of $80 \%$. The bacteriology and histology use permitted to establish the diagnosis. The direct bacteriological examination was positive on 5 specimens. The isolation of BK by culture was positive on 11 specimens. All the pieces were analyzed histologically confirmed the diagnosis on all of them, by showing a giant epithelial granuloma with central caseous necrosis.

Other associated tuberculosis localizations were diagnosed on five patients: 01 shoulder impairment, 03 lungs damages, and one patient had three concomitant locations (lung, shoulder, and knee). 
Table 3. Radiological lesions repartition of patients following David-Chausse’s classification.

\begin{tabular}{cc}
\hline Stages & Effective \\
\hline Stage I & 02 \\
Stage II & 05 \\
Stage III & 16 \\
Stage IV & 10 \\
\hline
\end{tabular}
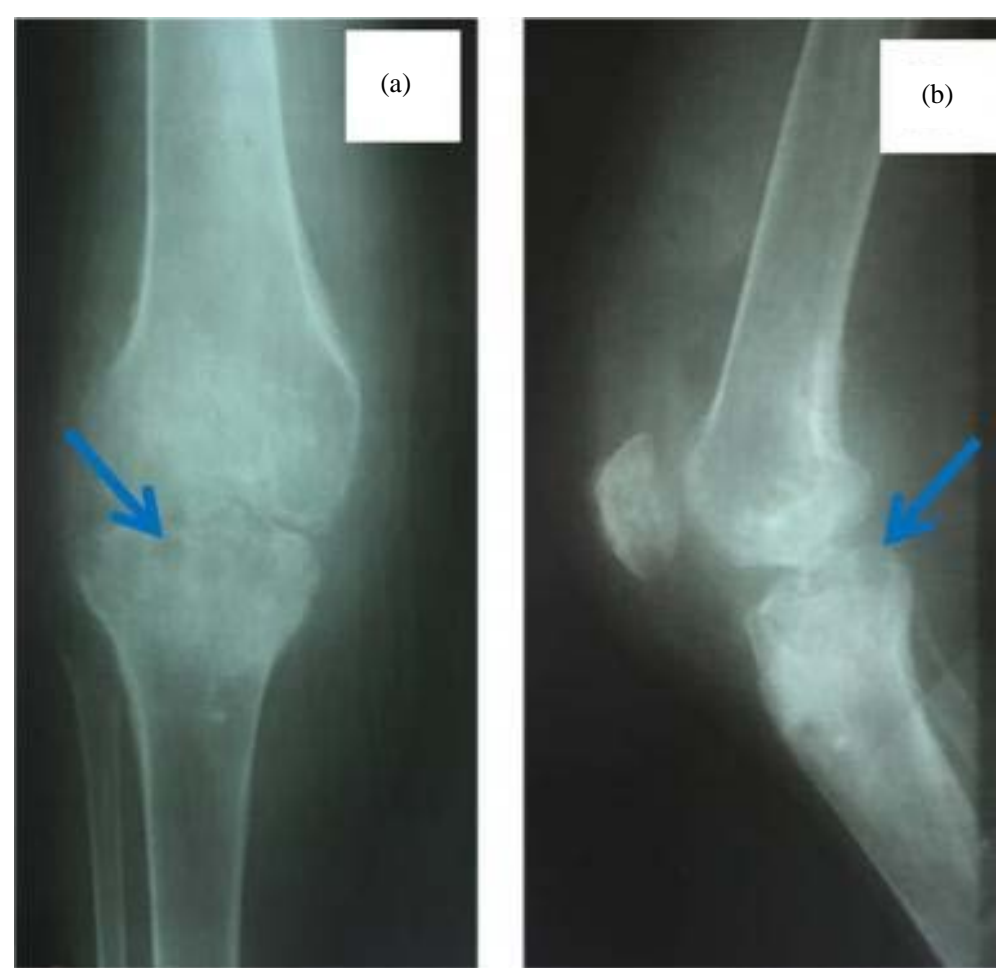

Figure 2. knee X-ray ((a) antero-posterior; (b) medio-lateral) showing osteoarthritis with many geodes and bone erosions, important pinching of joint space. Osteoarthritis stage III.
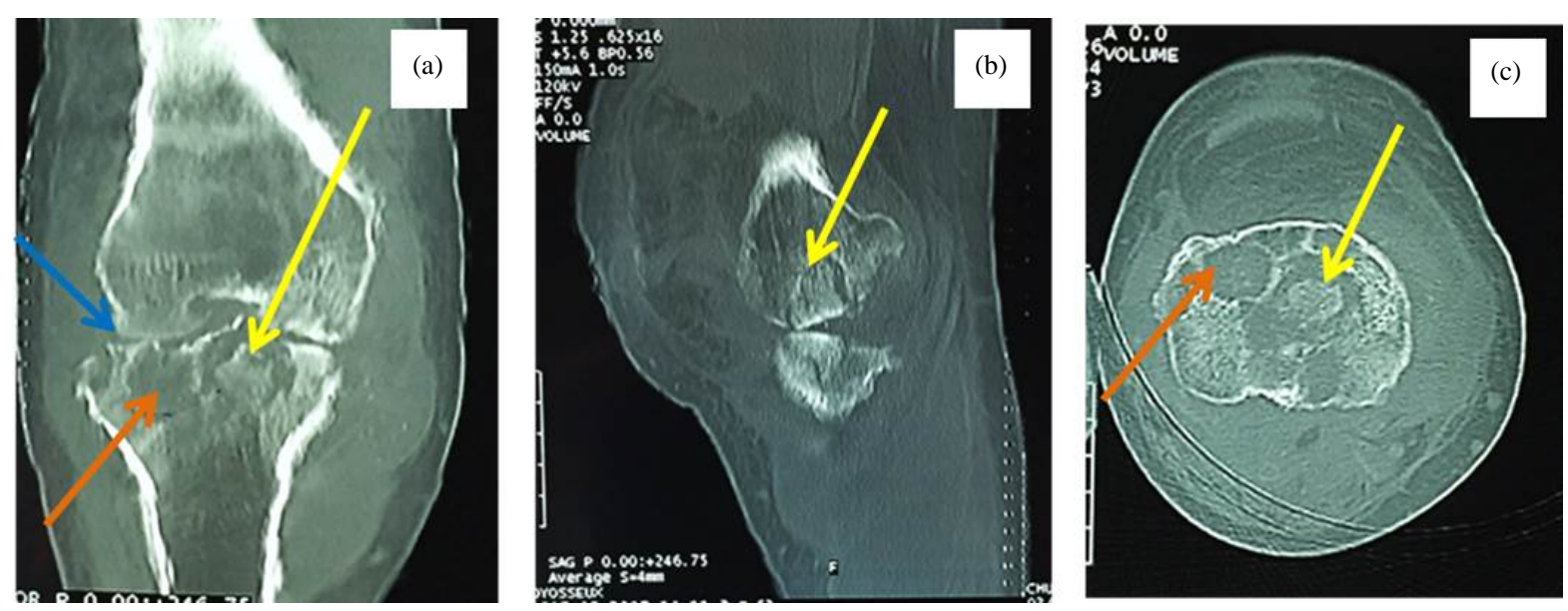

Figure 3. Knee CT-scan (coronal (a), axial (b) sagittawl (c)) showing pinching of joint space (arrow in blue), geodes epiphyseal (arrow in orange), images of sequestered bones at the level of femur and tibia (arrow in yellow). 

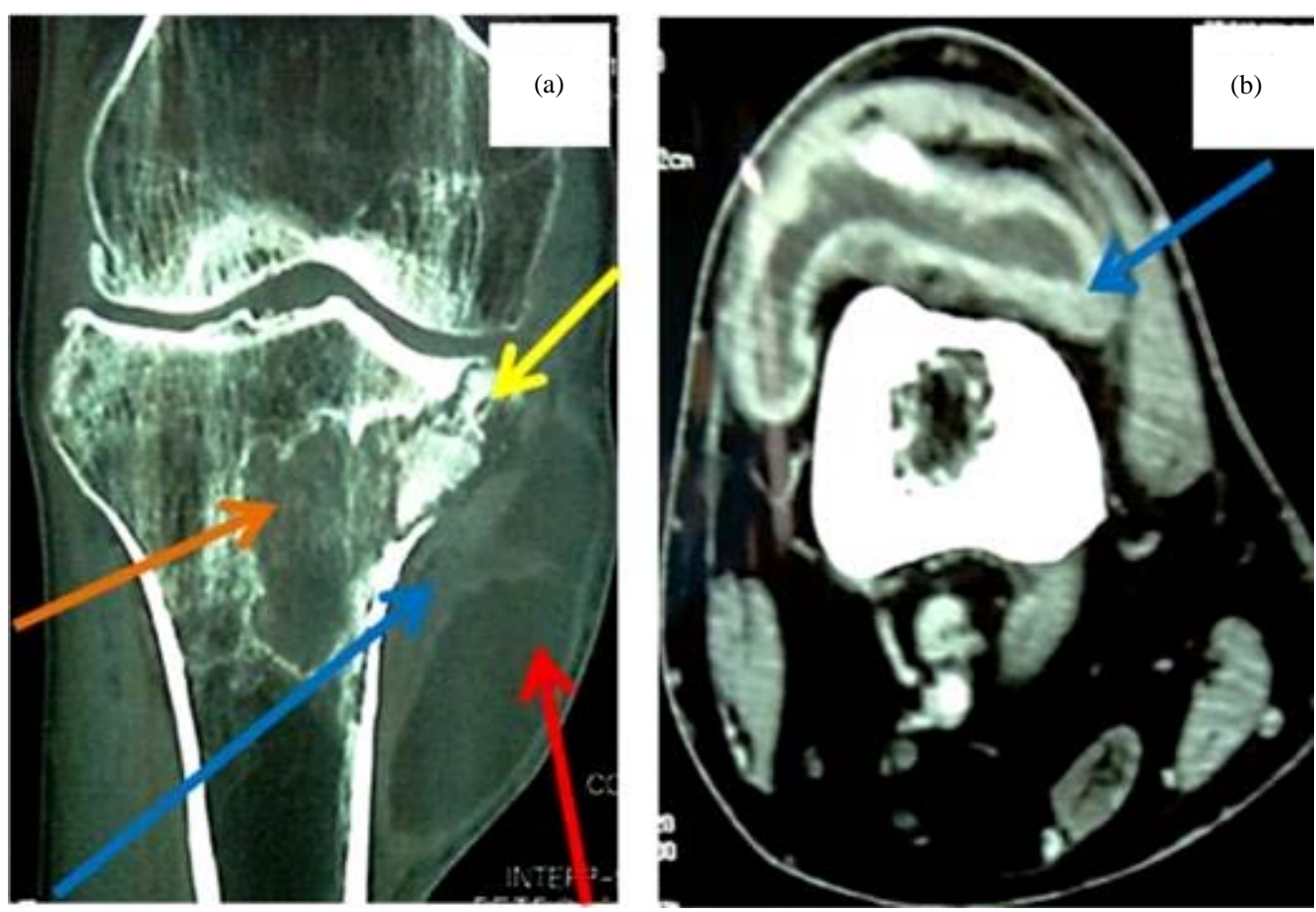

Figure 4. CT-scan of knee, ((a): coronal; (b): axial) showing: Big gap of metaphysis surrounded by a border of osteocondensation (arrow in orange); image of sequesters in bone Lysis (arrow in yellow), geodes under chondral; synovial thickening (arrow in blue), partitioning of the collection (arrow in red).

\subsection{Therapeutical and Evolutional Aspects}

For all of these patients, antitubercular poly chemotherapy was started according to the current plan (quad therapy since two months and dual therapy since ten months during one year). We did not noticed resistance during the treatment, but we noticed 8 cases of allergy.

During the arthrotomy, articular washing was systematic. Other surgical gestures were realized: synovectomy on 23 cases, sequestrectomy on 11 cases, and abscess drainage on 5 cases.

After a minimum of 18 months 03 deaths and 05 lost to follow-up were reported. The "Healing" of the bone and joint tuberculosis was noticed on all the revised $(n=25)$. No patient presented signs of infection or local recurrence.

At the functional plan, the algo-functional Lequesne index mean was important (pain or embarrassment 4/walking perimeter 3/Difficulty of the life 4,5 ). The radiographs assess noted residual post infectious lesions with knee ankylosis.

\section{Discussion}

Tuberculous arthritis predominates at the lower limbs in $60 \%-80 \%$ of cases [2]. On adults knee OAT, is became the most common localization (22\% - 59\%), before hip OAT (11\% - 19\%) [2]-[8].

However, in some studies [9]-[11], the hip location is the most common. In our series, tuberculosis of knee appears as exclusive young adult, mostly male. This male predominance is also found in some works [11] [12]. Opposed to them, Taarit [9] found a minor female predominance (52.77\%). Different studies agree to recognize an absence of gender discrimination [14] because the OAT can affect both sexes and all ages [2].

The orientating epidemiological arguments prevailed in our series were especially the notion TB contact and promiscuity corollary of a socio-economic disadvantaged situation. Other factors are involved: past pulmonary tuberculosis, HIV, transplanted patients, steroids treatment, elderly patients, substance abuse, diabetes or alcoholism, immigration, dialysis [2] [3].

Like Ntsiba [15] we are forced to notice that our patients consult lately (mean: 04 months).

In our regions, the resort to traditional therapist is actuality and could explain the delay in consultation, and 
the disease evolution is insidious. According to the literature, general signs frequencies vary between $25 \%$ and $45 \%$ of cases [2].

In this series, night fever, night sweat and weight loss were the most frequent (Table 1). Pain and swelling were the main consultations reasons found in our patients (93.10\%) and equally found in literature [5]-[12] The swelling seems to be due to the joint effusion but also to hypertrophy of the synovial membrane [2] [3] as testify the CT-scan image and the aspect during surgery (Figure 5).

Habitual clinical table is that of a sub-acute or chronic knee mono arthritis with a significant quadriceps amyotrophy, evolving towards a progressive aggravation in several weeks or months [2] [3] [12]. This arthritis can be isolated or sometimes associated with other localizations of tuberculosis as was the case on 5 patients. The frequency of multifocal forms is variable depending on the series, from $3 \%-20 \%$ of all cases [2]-[16].

In unusual tables, it will be necessary to eliminate other etiologies, like pyogenic arthritis, or systemic arthritis. Imagery is essential in this diagnostic discussion. It is the gold standard method in the study of articular effusion, because it permits to put on evidence pathognomonic bone and joint tuberculosis lesions [17] [18]. For some authors, abscess and sequestrum association inside the joint is suggestive to knee tuberculosis diagnosis [4] [5] [19] [20]. Imagery was poorly done in our study $(n=18)$ because of its high cost and non accessibility during a certain period of our study.

The gold standard method in the articular effusion study is synovial thickening, marginal erosions and the nearing articular or intra articular abscess [11]-[13].

For some authors, abscess and sequestrum association is suggestive to knee tuberculosis diagnosis [4] [5] [19] [20]. Bring out the Koch's Bacillus is essential for the diagnosis of knee OAT and also for the implementation of treatment.

In front of all chronical knee mono arthritis, articular puncture is obligatory (superficial joint) for acid-fast bacterium (AFB) research by direct exam and by culture on specific environment (Lowenstein or Jensen).

If in the literature, the bacteriology is positive in $50 \%-80 \%$ of cases [11]-[14], in our series, it was less contributive (23.08\% of cases). This difference could be explained by the conservation conditions, or transport samples condition and the availability of analytical laboratories. Moreover, the bringing out of AFB by culture is long (minimum 21 days). Currently through molecular biology, rapid diagnosis of tuberculosis is possible by the method of Polymerase Chain Reaction (PCR) (3 days). Unfortunately the cost for its realization seems high for our population. Certitude exam remains the histological exam of the piece of synovial biopsy.

Because of its rarity [4] [5], the knee white tumor diagnosis is not exempt of difficulties. In fact, some elements can attest this diagnosis: a primary infection sometimes unrecognized, an absence of a known focal tuberculosis point (pulmonary or extra pulmonary) with a normal immunity status, very insidious clinical manifestations

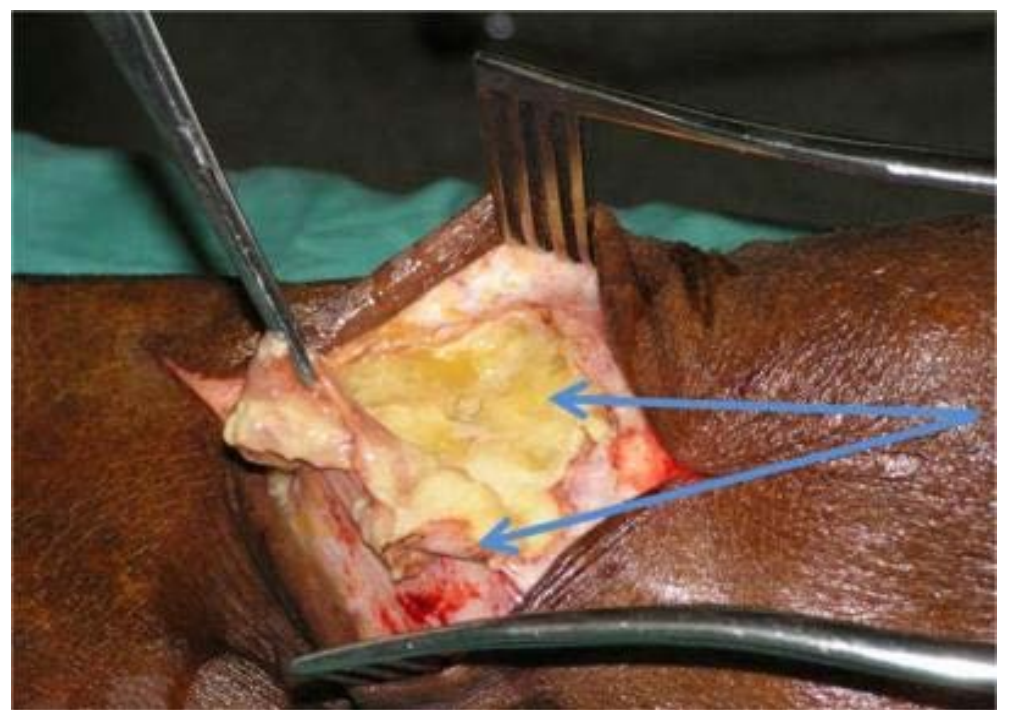

Figure 5. Local appearance per operating: arthrotomy anterior-medial on right knee, synovial thickening, appearance "cauliflower appearance” (arrow in blue). 
linked to chronicity; the delay of consultations. Also, the radiographic Phemister's triad is not specific as we think, Ti-T and bacteriological investigations on sample (puncture liquid, biopsy) which sometimes come-back negative or non-conclusive.

In front of these diagnosis difficulties, epidemiological, biological and imagery are essential for the diagnosis.

At the epidemiological plan, the of night fever, night sweat and weight loss on an active subject, from poor social and professional states, being good presumption arguments.

For us, in association to the arguments previously cited, in presence of partition articular collection or surrounded by a thickened synovial, intra articular abscess or sequestrum at the imagery and a sedimentation rate superior to $40 \mathrm{~mm}$ at $\mathrm{H} 1$ with an inflammatory anemia, tuberculosis etiology could be evoke even if the Ti-T is non-reactive or doubtful. They constitute actually the real arguments for biologic and imagery orientation. But, after all this, the element for certitude diagnosis stays the histological exam.

In our study, arthrotomy was contributive to the diagnosis, because permit the histological diagnosis on all the knees operated.

For some authors [12]-[21], the surgical treatment is no more systematic in the OAT, independently from the location because of the improvement of the medical treatment. In our working conditions, surgical treatment keeps its place in the therapeutic arsenal of the knee white tumor; as our consultation times are quite late, and that injuries are important; also because of our poor technical plate.

Arthrotomy presents many advantages. It permits to have the certitude diagnosis with the different samples, contribute to the infection control in association with the anti-tuberculous chemotherapy and so to preserve the joint function.

The evolution is only on treatment. The functional prognosis is best in the form treated early as far as the bacterial resistance problem is less important in the OAT [16]-[21]. Mesghani [22] obtained a good functional prognosis because of an early diagnostic and supported.

In our series, the functional result was bad due to the delay for consultation and so of technical support. We think as all the authors that only an early diagnosis is the veritable guarantee of a good functional result.

It is a pathology which affects a young active population. It stays severe under our tropics, because it is responsible of really disabling sequels (stiffness, pain and ankylose).

The treatment duration was only of 12 months on all our patients even if it varies from 9 to 18 months in the literature [2] [3].

After a minimum of 18 months we did not observed a local recurrence.

Despite this result, we can occult with certitude the possible apparition of local recurrence. J de Haan [23] had described one recurrence case of the knee white tumor after 61 years.

\section{Conclusion}

At the end of this cases series, profile of knee's bone and joint tuberculosis in adults is an active young man (average age 34), from an underprivileged socio-professional background. The diagnosis is often late. It is suspected in front of a chronic knee mono arthritis, in an array of evening fever, night sweat and weight loss. Imagery confirms the osteoarthritis lesions but a particular attention to the synovial thickening, to partition, the existence of sequestrum or nearing joint area or inside the joint. The diagnosis is sometimes tardive.

For us, a sedimentation rate higher than $40 \mathrm{~mm}$ at $\mathrm{H} 1$ associated to an anemia, oriented to the diagnosis even if the tuberculin intradermal test is non-reactive or questionable. Histology is the certitude exam. The delay before consultation and diagnosis, age and terrain are the main elements for prognostic.

One of limitations of our study is that, there was no control group to ensure that the reported comments are a coincidence. This is a retrospective and descriptive non-comparative study whose findings will be assessing by analytical studies (case-control, cohort).

\section{Conflict of Interests}

The authors declare no conflict of interest.

\section{Author's Contributions}

All the authors contributed to the writing of this manuscript and had read and approved the final version. 


\section{References}

[1] Rafiqi, K., Ait Lahcen, A., Messoudi, A., Rahmi, M., Fnini, S. and Garch, A. (2014) La tuberculose des os du pied à propos de 2 cas. Médecine et Chirurgie du Pied, 30, 62-66. http://dx.doi.org/10.1007/s10243-014-0385-8

[2] Pertuiset, E. (2006) Tuberculose ostéoarticulaire extravertébrale. Revue du Rhumatisme, 73, 387-393. http://dx.doi.org/10.1016/j.rhum.2005.10.019

[3] Annabi, H., Abdelkafi, M. and Trabelsi, M. (2008) La tuberculose ostéo-articulaire. Tunisie Orthopédique, 1, 7-17

[4] Araki, Y. and Tsukaguchi, I., Shino, K., et al. (1993) Tuberculous Arthritis of the Knee: MR Findings. American Journal of Roentgenology, 160, 664.

[5] Hamza, M. (1993)Tuberculose articulaire et vertébrale. Revue du Rhumatisme, 60, 115-118.

[6] Lequesne, M., Mery, C., Samson, M. and Gerard, P. (1987) Indexes of Severity for Osteoarthritis of the Hip and Knee. Scandinavian Journal of Rheumatology, 65, 85-89. http://dx.doi.org/10.3109/03009748709102182

[7] David-Chausse, J. (1979) Tuberculose ostéo-articulaire des membres. EMC, Appareil Locomoteur, 14185 A10, 9.

[8] Houshian, S., Poulsen, S. and Riegels-Nilesen, P. (2000) Bone and Joint Tuberculosis in Denmark. Increase Due to Immigration. Acta Orthopaedica, 71, 312-315. http://dx.doi.org/10.1080/000164700317411942

[9] Jellis, J.E. (2002) Human Immunodeficiency Virus and Osteoarticular Tuberculosis. Clinical Orthopaedics and Related Research, 398, 27-31. http://dx.doi.org/10.1097/00003086-200205000-00005

[10] Babhulkar, S. and Pande, S. (2002) Extraspinal Tuberculosis: Tuberculosis of the Hip. Clinical Orthopaedics and Related Research, 398, 93-99. http://dx.doi.org/10.1097/00003086-200205000-00013

[11] Daboiko, J.C., Ouédraogo, D.D., Eti, E., Nikiema, J.F., Gbané, M. and Kouakou N’Zué, M. (2005) Tuberculose ostéo-articulaire des membres. A propos de 16 cas. Medecine d'Afrique Noire, 5266, 329-332.

[12] Oueslati, S., Douira, W., Charada, L., Mlika, L., Rezgui, L., Zaouia, K., et al. (2007) IRM de l'arthrite tuberculeuse du genou. Médecine et Maladies Infectieuses, 37, 549-553. http://dx.doi.org/10.1016/j.medmal.2006.10.006

[13] Taarit Ben, C., Turki, S. and Maïz Ben, H. (2003) La tuberculose ostéo-articulaire en Tunisie: Etude rétrospective de 180 cas. Médecine et Maladies Infectieuses, 33, 210-214. http://dx.doi.org/10.1016/S0399-077X(03)00009-X

[14] Eschard, J.P., Leone, J. and Etienne, J.C. (1993) Tuberculose ostéo-articulaire des membres. Editions Techniques, EMC, Appareil Locomoteur, 14185 A10, 15.

[15] Ntsiba, H., Bazébissa, R., Lamini, N. and Yala, F. (2004) Cent cas d'arthrite septique du genou en zone intertropicale. Bulletin de la Société de Pathologie Exotique, 97, 244-246.

[16] Tuli, S.M. (2002) General Principles of Osteoarticular Tuberculosis. Clinical Orthopaedics and Related Research, 398, 11-19. http://dx.doi.org/10.1097/00003086-200205000-00003

[17] Graif, M., Schweitzer, M.E., Deely, D. and Matteucci, T. (1999) The Septic Versus Non-Septic Inflamed Joint: MRI Characteristics. Skeletal Radiology, 28, 616-620. http://dx.doi.org/10.1007/s002560050562

[18] Hong, S.H., Kim, S.M., Ahn, J.M., Chung, H.W., Shin, M.J. and Kang, H.S. (2001) Tuberculous Versus Pyogenic Arthritis: MR Imaging Evaluation. Radiology, 218, 848-853. http://dx.doi.org/10.1148/radiology.218.3.r01fe27848

[19] Malaviya, A.N and, Kotwal, P.P. (2003) Arthritis Associated with Tuberculosis. Best Practice \& Research Clinical Rheumatology, 17, 319-343. http://dx.doi.org/10.1016/S1521-6942(02)00126-2

[20] Engin, G., Acuna, B., Acuna, G. and Tunaci, M. (2000) Imaging of Extrapulmonary Tuberculosis. RadioGraphics, 20, 471-488. http://dx.doi.org/10.1148/radiographics.20.2.g00mc07471

[21] Pertuiset, É. (2006) Traitement médical et chirurgical de la tuberculose ostéoarticulaire. Revue du Rhumatisme, 73, 401-408. http://dx.doi.org/10.1016/j.rhum.2005.10.020

[22] Mezghani, S., Hamdi, S., Laadhar, H., Tchousso Zatao, O., Chaniour, M., Hayouni, A., et al. (2003) La tuberculose extrapulmonaire. Revue des Maladies Respiratoires, 20, 153-166.

[23] De Haan, J., Vreeling, A.W.J. and Van Hellemont, G.G. (2008) Reactivation of Joint Tuberculosis of Knee Following Total Knee Arthroplasty after 61 Years: A Case Report. The Knee, 15, 336-338. http://dx.doi.org/10.1016/j.knee.2008.03.004 